\title{
Insights into In Vitro Biokinetics Using Virtual Cell Based Assay Simulations
}

\author{
Susana Proença1,2, Alicia Paini 1, Elisabeth Joossens ${ }^{1}$, Jose Vicente Sala Benito 1, Elisabet Berggren 1, \\ Andrew Worth 1, Maurice Whelan 1 and Pilar Prieto ${ }^{1}$ \\ ${ }^{1}$ European Commission, Joint Research Centre, Ispra, Italy; ${ }^{2}$ Institute for Risk Assessment Sciences, Utrecht University, Utrecht, The Netherlands
}

\begin{abstract}
The Virtual Cell Based Assay (VCBA) is an in silico model that simulates the biokinetics of chemicals in in vitro test systems. VCBA simulations can indicate the degree to which the bioavailable concentration varies across chemicals and experimental conditions, thereby providing important contextual information for comparing the results of different in vitro toxicity experiments. The simulated results can also be used to support in vitro to in vivo extrapolation of toxicity data, especially when the VCBA is coupled to a physiologically based kinetic model.

In this work, we selected 83 chemicals previously tested for in vitro cytotoxicity with a neutral red uptake (NRU) assay and used the respective in vitro data to optimize a toxicity and effects model simulating the 3 T3 BALB/c cell line in a 96-well microplate with 5\% serum supplementation. We then used the optimized parameters to simulate alternative experimental conditions. The simulations show the impact of different physicochemical properties on chemical fate of this diverse group of chemicals and how the different partitioning (to protein, lipid, and plastic) and kinetic (evaporation and degradation) events are intrinsically connected. The results of VCBA simulations were interpreted with respect to the applicability domain of the different QSARs incorporated in the model and the underlying assumptions and uncertainties of the VCBA.
\end{abstract}

\section{Introduction}

The increasing need to test chemicals for risk assessment and the ethical and scientific concerns over animal experimentation have brought in vitro models into the limelight. They have been proposed as a more efficient and economical model that is compliant with the 3 Rs principles (replacement, reduction, and refinement of animal testing).

Considering that toxicological events are mostly initiated at the cellular level (Ekwall, 1983; Schirmer, 2006), in vitro methods are not only relevant to screen for these events but also to better understand their mechanisms of action. Such information may help to identify other chemicals with similar mechanisms. In vitro methods encompass a wide range of cell types, culture methods, and experimental conditions. The chemical concentrations tested in these models represent concentrations that are bioavailable to the organ and not actual exposure doses. Therefore, to extrapolate observed in vitro toxic doses to respective in vivo exposure doses in a quantitative way (QIVIVE), in silico mod- elling of the pharmacokinetic processes of absorption, distribution, metabolism, and excretion (ADME) is needed (Andersen and Krishnan, 1994; Coecke et al., 2013; Ferrarini et al., 2013; Groothuis et al., 2013; Louisse et al., 2016; Bell et al., 2018).

For this purpose, several physiologically-based kinetic (PBK) models have been developed, many of which are compiled in Lu et al. (2016). For PBK models to fully conform with the 3Rs, their chemical-specific input parameters should be derived from non-animal sources, including in vitro models, provided that any limitations and uncertainties are considered and stated explicitly. Although ideal from a 3 Rs perspective, this strategy poses challenges related to the validation and acceptance of the models by end-users (Paini et al., 2019).

To correctly evaluate a kinetic parameter such as clearance of a chemical, all relevant in vitro biokinetic processes should be identified and quantified as they are likely to influence the bioavailable chemical concentration. The in vitro experimental setting, i.e., cells in aqueous medium, frequently including serum in different percentages, in a plastic vessel that is in contact with
Received December 10, 2018; Accepted March 28, 2019;

Epub March 28, 2019; @ The Authors, 2019

ALTEX 36(3), 447-461. doi:10.14573/altex.1812101

Correspondence: Pilar Prieto, $\mathrm{PhD}$

European Commission, Joint Research Centre,

Directorate F - Health, Consumers and Reference Materials,

Chemical Safety and Alternative Methods Unit,

EURL ECVAM, Ispra, Italy

(pilar.prieto-peraita@ec.europa.eu)
This is an Open Access article distributed under the terms of the Creative Commons Attribution 4.0 International license (http://creativecommons.org/licenses/by/4.0/) which permits unrestricted use, distribution and reproduction in any medium, provided the original work is appropriately cited. 

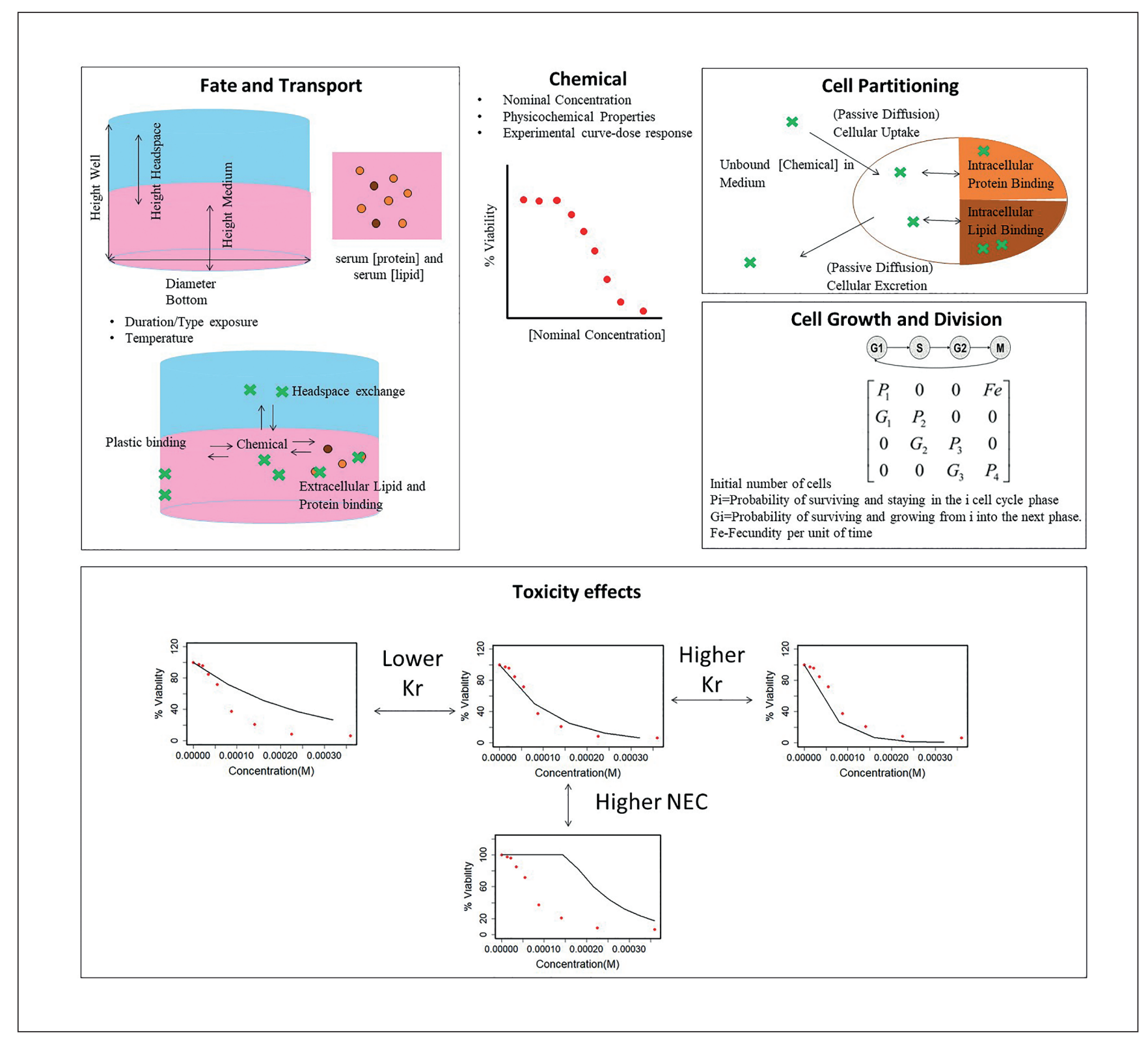

Fig. 1: Schematic representation of the 4 interconnected models of the virtual cell based assay (VCBA) used to simulate the kinetics of a test chemical

$\mathrm{Kr}$, the rate constant for the killing rate increases as a function of the chemical concentration; NEC, no effect concentration for survival

air, is an environment that is drastically different from the in vivo microenvironment of cells. Indeed, binding of chemicals to serum proteins and lipids, plastic, and evaporation (Kramer, 2010; Stadnicka-Michalak et al., 2014; Seibert et al., 2002; deBruyn and Gobas, 2007), have been broadly described to considerably impact the actual chemical concentration in in vitro systems. Moreover, the most commonly used dose metric in in vitro systems is the added (nominal) concentration, which does not reflect the amount of chemical per number of cells in the system. Gülden et al. (2001) showed that free concentration and toxic effects change with cell number, i.e. higher cell numbers in culture have higher $\mathrm{EC}_{50}$ values.
Therefore, a better approximation of in vivo toxic concentrations may be obtained by modulating these in vitro biokinetic processes to determine the concentration that is effectively dissolved in the exposure medium and is unbound (free concentration). Indeed, chemicals that have higher cytotoxic potencies are affected more strongly by these biokinetic events than chemicals that have lower cytotoxicity potencies, as the amount of non-bioavailable chemical can easily surpass the bioavailable amount. In the case of less toxic chemicals, the impact of serum binding may be negligible if the nominal toxic concentration exceeds the binding capacity of the serum proteins (Gülden and Seibert, 2005). Heringa et al. (2004) showed that while nominal 
$\mathrm{EC}_{50}$ values depend on serum percentages, the freely available $\mathrm{EC}_{50}$ values are roughly the same. Ideally, this in vitro biokinetics translation of nominal to free concentration of chemicals can be integrated into PBK models (Gajewska et al., 2015; Paini et al., 2017a) and quantitative adverse outcome pathways (qAOPs) (Madureira et al., 2014).

The Virtual Cell Based Assay (VCBA) is an in silico model developed as part of the EU FP7 COSMOS project ${ }^{1}$ (SEURAT-1). It simulates in vitro chemical fate and intracellular concentrations to determine the free concentration that is required to cause perturbations in cells (Zaldívar Comenges et al., 2010, 2011). Briefly, to run the VCBA, specific input parameters for chemicals, cell types, and experimental set-up are needed. The VCBA consists of 4 interconnected models (Fig. 1):

1 Fate and transport model, which is based on each chemical's physicochemical properties. It describes the dynamic mass balance of a given chemical, including its partitioning between headspace (gas exchange equations), plastic, and serum lipid (deBruyn and Gobas, 2007; Kramer, 2010), as well as chemical degradation;

2 Cell partitioning model, which describes cell uptake/excretion, and the intracellular partitioning between lipid, protein, and aqueous fractions, which depends on the chemical characteristics and cell type composition;

3 Cell growth and division model, which is simulated by a 4-stage (G1, S, G2, and M cell cycle phases) approach using a Leslie matrix. Depending on the cell type, cell growth and division can be adjusted (Paini et al., 2017b).

4 Toxicity and effects model, which merges the experimental in vitro concentration-response curve with the cell growth and division model to fit the toxicity parameters, i.e., the no-effect concentration (NEC) and killing rate $(\mathrm{Kr})$. Briefly, VCBA simulates the cell growth for all nominal concentrations of the experimental concentration-response curve and it calculates the intracellular concentration for each nominal concentration. First, a random threshold is used at which the NEC starts to cause cell death $(\mathrm{Kr})$, hence obtaining the percentage of viability for all nominal concentrations. Then, in order to minimize the error between the experimental and the predicted concentration-response curve, the sum of errors is calculated. Next, the NEC and Kr, are changed to create another concentration-response curve and the error is calculated. Finally, using the optimum function in R (general-purpose gradient optimization function) and following the optimization approach described by Zaldívar and Baraibar (2011), NEC and Kr are changed to decrease the sum of errors.

Further, the VCBA considers the experimental set-up, which includes the well shape and size, the volume of medium, and the amount of supplemented serum and, thus, protein and lipid content in the media. The mathematical equations describing the four interconnected models of the VCBA are reported in (Zaldivar Comenges et al., 2017). More information on the VCBA can be found in (Paini et al., 2017b; Graepel et al., 2017; Sala Benito et al., 2017; Worth et al., 2017).

The overall goal of this work was to apply the VCBA to a large set of chemicals, for which in vitro acute oral toxicity data were already available, to clarify which experimental conditions and physicochemical properties have the greatest impact on in vitro chemical fate. A subset of 83 chemicals tested in international projects and validation studies (NICEATM/ECVAM validation study (NIH, 2006); the PF6 EU project ACuteTox ${ }^{2}$ (Prieto et al., 2013a); ECVAM validation study (Prieto et al., 2013b)) was chosen. The complete list of chemicals used in these projects can be found in the EC-JRC Chemical Lists Information System, CheList $^{3}$. In all of these projects, the BALB/c 3 T3 cell line was used and cytotoxicity was measured with a neutral red uptake (NRU) assay. Hence, the VCBA model was set to simulate the conditions of the NRU assay with some experimental variability to characterize the uncertainties of the VCBA core model, and to estimate the dissolved or intracellular chemical concentration that can be used for different in vitro comparisons and as a point of departure for QIVIVE.

\section{Materials and methods}

\section{Estimation of chemical parameters}

The following physicochemical parameters are required to run the VCBA:

1. Molecular weight (MW; g/mol);

2. Molecular diffusion volume (SVcomp, indicated as atomic diffusion in Zaldívar Comenges et al. (2017))

3. Molar volume (MV; $\left.\mathrm{cm}^{3} / \mathrm{mol}\right)$;

4. Henry law constant (HLC; $\mathrm{Pa} \times \mathrm{m}^{3} / \mathrm{mol}$ );

5. Degradation rates in water and air $\left(\mathrm{s}^{-1}\right)$;

6 . The logarithm of the octanol-water partition coefficient (log$\mathrm{K}_{\mathrm{ow}}$ ) (unitless).

The physicochemical parameters of the 83 chemicals were collected between July 2016 and October 2016. Molecular weight was retrieved from the EPA Chemical Dashboard ${ }^{4}$, and water and air degradation rates were derived from the half-life reported by EPI Suite ${ }^{\mathrm{TM}}$ (US Environmental Protection Agency) by applying the following formula: $\mathrm{k}_{\mathrm{deg}}=\ln / \mathrm{t}_{(1 / 2)}$. Molar volume was retrieved from $\mathrm{ACD} / \mathrm{Labs}^{5}$ software predictions retrieved from Chemspider 6 , and when not available it was extrapolated from the MW through a simple linear equation, as indicated in Proença et al. (2017). Molecular diffusion volume (dimensionless), required for fugacity prediction, was calculated by the Fuller semi-empirical method as the sum of the specific atomic diffusion volumes, discounting the volume of each aromatic/heterocyclic ring (Fuller

\footnotetext{
$1 \mathrm{http}: / /$ www.cosmostox.eu (accessed 08.03.2019).

2 http://www.acutetox.eu/ (accessed 08.03.2019).

3 http://chelist.jrc.ec.europa.eu/index.jsp?id=2\&id_list=43 (accessed 08.03.2019).

4 https://comptox.epa.gov/dashboard (accessed 08.03.2019).

5 https://www.acdlabs.com/ (accessed 08.03.2019).

6 http://www.chemspider.com/ (accessed 08.03.2019).
} 
Tab. 1: Cell line (3T3 Balb/c) parameters used to run the VCBA model

\begin{tabular}{|c|c|c|c|c|}
\hline Aqueous fraction (\% weight) & \multicolumn{4}{|l|}{0.614} \\
\hline Protein fraction (\% weight) & \multicolumn{4}{|l|}{0.244} \\
\hline Lipid fraction (\% weight) & \multicolumn{4}{|l|}{0.142} \\
\hline Protein concentration $\left(\mathrm{mol} / \mathrm{m}^{3}\right)$ & \multicolumn{4}{|l|}{4.4} \\
\hline Lipid concentration $\left(\mathrm{kg} / \mathrm{m}^{3}\right)$ & \multicolumn{4}{|l|}{170.7} \\
\hline Cell cycle phase & G1 & S & G2 & $M$ \\
\hline Duration $(\mathrm{H})$ & 9.63 & 3.65 & 3.45 & 2.26 \\
\hline Mortality $\left(\mathrm{h}^{-1}\right)$ & 0.005 & 0.005 & 0.04 & 0.04 \\
\hline Volume $\left(\mathrm{m}^{3}\right)$ & $1.73 \mathrm{E}-15$ & $2.4 \mathrm{E}-15$ & $2.4 \mathrm{E}-15$ & $2.4 \mathrm{E}-15$ \\
\hline Mass (g) & $2.08 \mathrm{E}-9$ & $2.4 \mathrm{E}-9$ & $2.4 \mathrm{E}-9$ & $2.4 \mathrm{E}-9$ \\
\hline Initial cell population (\%) & 50.7 & 19.2 & 18.18 & 11.92 \\
\hline Cell division rate $\left(h^{-1}\right)$ & 1.026 & & & \\
\hline
\end{tabular}

Tab. 2: Experimental set-up based on the 3T3 Neutral Red Uptake protocol and used for the virtual cell based assay (VCBA) simulations

\begin{tabular}{|l|l|l|l|}
\hline \% Supplemented serum & $\mathbf{0}$ & $\mathbf{5}$ & $\mathbf{1 0}$ \\
\hline Protein in medium $\left(\mathbf{m o l} / \mathbf{m}^{3}\right)$ & 0 & 0.0234 & 0.0468 \\
\hline Lipid in medium $\left(\mathbf{k g} / \mathbf{m}^{3}\right)$ & 0 & 0.08 & 0.16 \\
\hline Type of well plate & 96 -well plate & 24 -well plate & 6 -well plate \\
\hline Number of cells & 1680 & 10,000 & 50,500 \\
\hline Volume medium $\left(\mathbf{m}^{3}\right)$ & $1 \mathrm{E}-7$ & $6.04 \mathrm{E}-07$ & $3.00 \mathrm{E}-06$ \\
\hline Diameter top $(\mathbf{m})$ & 0.00685 & 0.0156 & 0.0348 \\
\hline Diameter bottom $(\mathbf{m})$ & 0.00635 & 0.0156 & 0.0348 \\
\hline Depth $(\mathbf{m})$ & 0.01076 & 0.01779 & 0.01766 \\
\hline
\end{tabular}

et al., 1966, 1969). For chemicals requiring atom diffusion volumes, and for which the atom increments were not available, an extrapolation from MW was also made. A local sensitivity analysis of the VCBA showed that variations of the atom diffusion volumes and the molar diffusion only slightly impact the predicted unbound medium concentration results, thus there is no need for highly accurate parameters (Proença et al., 2017).

Both experimental and predicted values of the HLC were available in both EPIsuite and Chemical Dashboard. Priority was given to experimental values; if more than one value was found, the average was used. When no experimental data was available, priority was given to EPIsuite predictions, first the Group Method, then the Bond Method, and finally Chemical Dashboard, which uses several prediction models and presents the average value.

$\log \mathrm{K}_{\mathrm{ow}}$ values were researched in both Chemspider (Royal Society of Chemistry) and Chemical Dashboard, again giving priority to experimental values, and using the average when suitable. When predicted values had to be used, priority was given to Chemical Dashboard, which uses a revised database in pre- diction-model development. In the absence of such predictions, the average of the other predictive tools in Chemspider was used.

\section{Cell line parameters}

The values used (Tab. 1) were taken from our previously published work (Zaldívar Comenges et al., 2017) except for the intracellular protein concentration, which was recalculated and set to $4.4 \mathrm{~mol} / \mathrm{m}^{3}$, based on protein density, protein fraction in the cell, and cell volume.

The cell division rate parameter does not consider cellcell contact growth inhibition; this cell line reaches confluence at 50,000 cells $/ \mathrm{cm}^{2}$, after which the cells halt their growth. However, the initial cell numbers and assay time used describe a non-confluency scenario.

\section{Experimental set-up}

The experimental parameters, such as the different well-plates and serum percentages used, are illustrated in Table 2. These conditions were based on those used in the scope of the ACute- 


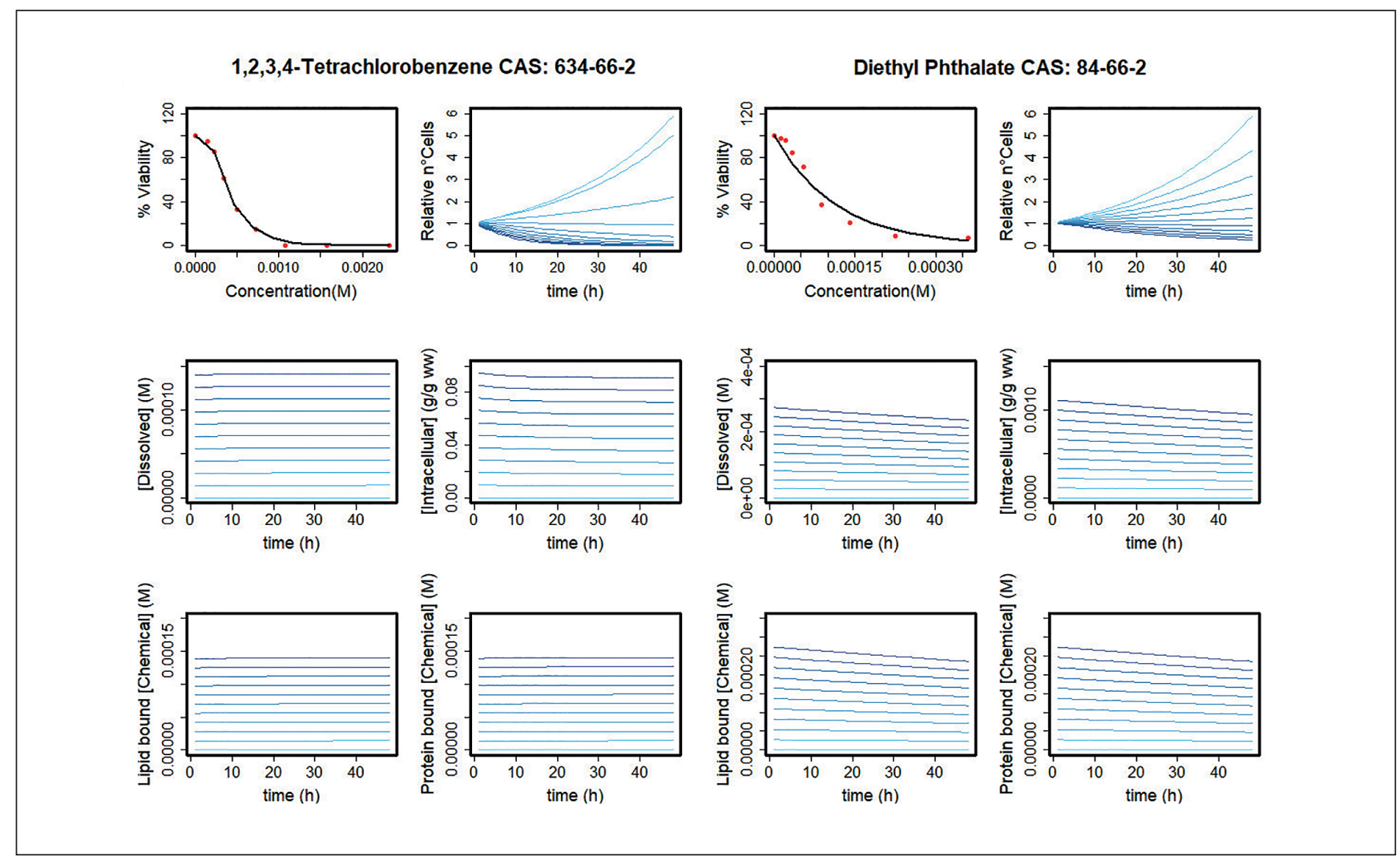

Fig. 2: Optimization of NEC and Kr, and modelling chemical fate and effects in the cell population for 1,2,3,4-tetrachlorobenzene and diethyl phthalate

In each panel, the top left plot shows the optimization of the concentration-response relationship by comparing cell viability after 48 hours (black lines) against experimental data (red dots). The top right plot shows the effect of the chemical's concentration (Molar or gram per gram wet weight) relative to the number of cells during the 48-hour assay for several nominal concentrations. For 1,2,3,4-tetrachlorobenzene the simulated concentrations ranged from 0 to $0.00232 \mathrm{M}$ and for diethyl phthalate from 0 to $3.6 \times 10^{-4} \mathrm{M}$. The remaining plots show the unbound, intracellular, lipid and protein bound concentrations over time. For all plots except the first, 10 concentrations were modelled and are represented by shades of blue from lower (light color) to higher concentrations (darker color).

Tox project for $3 \mathrm{~T} 3$ cells: initial number of 1680 cells, 48 hours in a 96 -well plate with $10 \%$ FBS in $100 \mu 1$ medium (DB-ALM protocol $139^{7}$ ). Then, the volume of medium and cell number in the different in vitro set-ups were selected in proportion to the surface area. The densities of the phases were set to: water = $1000 \mathrm{~g} / \mathrm{l}$, proteins $=1350 \mathrm{~g} / \mathrm{l}$, and lipids $=900 \mathrm{~g} / \mathrm{l}$, as previously reported in Zaldívar Comenges et al. (2017).

\section{Optimization and running of the VCBA}

$\mathrm{NEC}$ and $\mathrm{Kr}$ are both chemical- and cell line-specific, and were obtained using the experimental results, as explained above in the introduction to the VCBA model.

Optimization of NEC and $\mathrm{Kr}$ was done by calculating the partitioning of each chemical and integrating it with the experimental concentration-response curves from the ACuteTox project, consisting of eight concentrations and a value linked to the con- trol response (which is included as a response of $100 \%$ at $0 \mu \mathrm{M}$ ). The experimental set-up that was used to obtain this data was based on a 48-hour assay with 5\% serum and in a 96-well plate.

After the NEC and $\mathrm{Kr}$ were optimized by minimizing the residuals between the experimental and theoretical response curves, they were used within the model to further study the impact of different set-ups on the concentration of chemical in the various compartments, by keeping them constant but changing the experimental set-up parameters.

The code $^{8}$ was developed using $\mathrm{R}$ software, version 3.3.1, with cell growth given in hours and differential equations solved using a discretization in seconds. This specific time was chosen to speed up optimization, as cell growth/death in minutes would require VCBA to run more cycles, slowing down the optimization process. Moreover, since cell cycle phases take several hours rather than minutes, running the cycle in minutes would

\footnotetext{
7 https://ecvam-dbalm.jrc.ec.europa.eu/methods-and-protocols/search/139 (accessed 08.03.2019).

8 doi:10.14573/altex.1812101s1
} 
not necessarily better resemble the physiological growth. The $\mathrm{R}$ code for running the simulations has been included into a KNIME workflow to automate the model and make it easier to use without the need for programming skills.

\section{Statistical analysis}

R studio and GraphPad Prism 3.0 (San Diego, CA) were used to plot and analyze the data.

\section{Results}

The 83 substansces with a range of physicochemical properties $\left(\log \mathrm{K}_{\mathrm{ow}}=-4.5\right.$ to $10.3 ; \mathrm{HLC}=9.66 \times 10^{-34}$ to $1.74 \times 10^{3}$; and $\mathrm{MW}$ $=41$ to 823 ) were modelled in the VCBA, with their NEC and $\mathrm{Kr}$ optimized against the experimental concentration-response curves, as presented in the supplementary file ${ }^{9}$. Figure 2 illustrates, for 1,2,3,4-tetrachlorobenzene and diethyl phthalate, how the VCBA fits the toxicological parameters against the experimental data, and how it models chemical fate and the effect of several concentrations on cell number. Although the fitting was optimal for some chemicals (the lowest sum of the residual squares was 15 for glycerol), the error was much higher for others (the lowest sum of the residual squares was 5313 for benz(a) anthracene).

Modelling the relation between cell number and chemical concentration (Fig. 2), accounting for both growth and toxicity effects, best illustrates how viability decreases with time. The plot for intracellular concentration of diethyl phthalate (Fig. 2) indicates a virtually immediate cell uptake, in which the slight decrease over time is accompanied by a decrease also in dissolved concentration. The partitioning of chemical to plastic, serum lipid and protein is also instantaneous (not shown here); hence these events are not the cause of the decrease of concentration over time. Since both $3 \mathrm{~T} 3 \mathrm{BALB} / \mathrm{c}$ cells and the VCBA model do not include chemical metabolism, the causes of this decrease are evaporation and/or degradation. In fact, after 48 hours exposure there was a loss of $14 \%$ of the chemical mass due to diethyl phthalate degradation and less than $0.1 \%$ mass in headspace.

\subsection{Influence of $\log K_{o w}$ and HLC in chemical partitioning} The binding of chemicals to lipids, protein and plastic is modelled as achieving equilibrium instantaneously, and is thus not considered a rate-limiting step; however, it does affect the bioavailable/unbound concentration during the whole assay duration as lipids, protein and plastic act as chemical reservoirs. Figure 3 shows the extracellular partitioning after 48 hours, where the nominal concentration is the experimentally obtained $\mathrm{EC}_{50}$ value, hence a concentration that induces cell death. Even though the model requires additional chemical descriptors, which vary widely among the chemicals, this influence is clearly observed by sorting the chemicals from the highest to the lowest $\log \mathrm{K}_{\mathrm{ow}}$ and plotting their modelled partitioning (Fig. 3). Accord- ing to the cut-off value in Equation 3, less than 10\% of the chemical was unbound in the medium for the 14 chemicals with a $\log \mathrm{K}_{\mathrm{ow}}$ higher than or equal to 4.46 (phenantrene has a $\log \mathrm{K}_{\mathrm{ow}}$ of 4.46). For different $\log \mathrm{K}_{\mathrm{ow}}$ ranges, different elements of the in vitro system will be the main sequesters of the chemical. Observing Figure 3 from bottom to top, from 1.88 (triethylene glycol dimethacrylate) to higher $\log \mathrm{K}_{\mathrm{ow}}$ values, the unbound amount decreases as the amount of protein-bound chemical increases until $\log \mathrm{K}_{\mathrm{ow}} 3.83$ (endosulfan), where lipid gradually binds more chemical, eventually sequestering chemical from protein binding. Although there is significant binding to plastic, it is never more than $18 \%$.

Regarding evaporation, the VCBA model indicates that only for the two chemicals with higher HLC values, benzene (HLC = $562 \mathrm{~Pa} \times \mathrm{m}^{3} / \mathrm{mol}$ ) and xylene (HLC $\left.=525 \mathrm{~Pa} \times \mathrm{m}^{3} / \mathrm{mol}\right)$, the percentage of chemical that evaporates is greater than $10 \%$. In contrast, for 1,2,4-trichlorobenzene, with an HLC of $144 \mathrm{~Pa} \times \mathrm{m}^{3} / \mathrm{mol}$, only $1 \%$ is predicted to evaporate.

Although chemical partitioning has a high impact on its unbound concentration after 48 hours, degradation also plays a role and is considered in the VCBA model. The ratio between nominal (total initial) amount and final amount (sum of the amount of chemical that is unbound, bound to protein, lipids, plastic, in headspace and intracellular after the $48 \mathrm{~h}$ assay period) was assumed to be an indication of the chemical's effective degradation:

$\%$ Chemical degraded $=100-\frac{\text { Final Amount }}{\text { Nominal Amount }} \times 100$

The percentage of degraded chemical and related descriptors are shown in Table 3. In spite of both chemicals not having especially high degradation rates, xylene stands out with the highest degradation (38\%), followed by ethanol (14\%). Since the degradation rate is in general higher in air than in water, volatile compounds will tend to degrade faster, which highlights the importance of the HLC as an indicator of in vitro fate. It is also noteworthy that the overall degradation of a chemical does not depend solely on specific degradation rates but also on its partitioning behavior. The percentage degradation has no apparent correlation with air degradation, while for water degradation there is a trend. These degradation rates will only affect chemicals that are unbound, either in the aqueous or the gas phase. Chemical bound to protein, lipid, or plastic is considered to be "protected" from degradation in the VCBA. Analyzing all these parameters together (Tab. 3) using a color scale pattern shows that the actual degradation of chemicals in an in vitro experiment is a multifactorial process.

\subsection{Influence of the experimental set-up on chemical partitioning}

As binding to plastic, extracellular lipid and protein affects the amount of unbound chemical so greatly, it was explored how different in vitro set-ups further influence the partitioning behavior. Sixteen chemicals from the initial set of 83 were selected to cover a wide range of $\log \mathrm{K}_{\mathrm{ow}}$ values (from dimethyldioctadecylammonium chloride with 8.392 to ammonium chloride with -2.68 ),

9 doi:10.14573/altex.1812101s2 

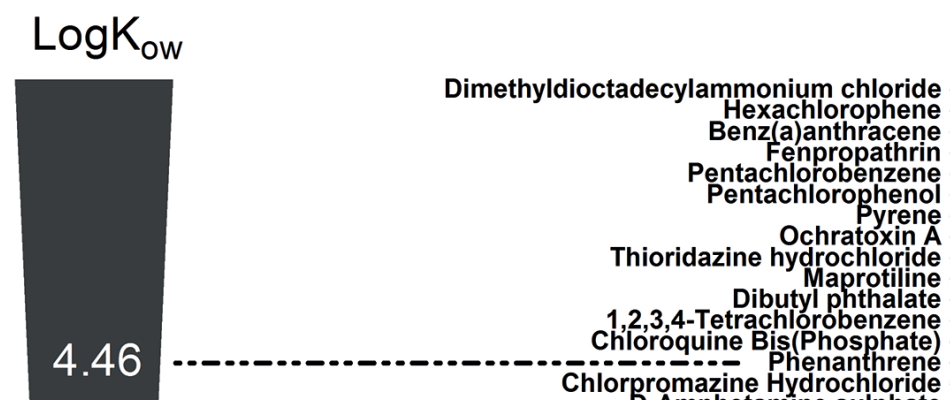

Chlorpromazin

D-Amphetamine sulphate

Amitriptyline Hydrochloride
4'-Tert-Butyl-2'6'-Dimethyl-3'5'-Dinitroacetophenone

Methadone hydrochloride

1,2,4-Trichiorobenzene

Benzyl benzoate

Rifampicin

Endosulfan

17a-Ethynyloestradiol
Triphenyltin hydroxide N-isopropyl-N'-phenyl-p-phenylenediamine Ethoxyquin Warfarin

Caprylic acid

Propylparaben Valproic acid

2,4-Dichlorophenoxyacetic acid

Diethyl phthalate

Carbamazepine

2.6-Diethylaniline

2-Chloro-4-nitroaniline

1-Naphthylamine

Triethylene glycol dimethacrylate

Phthalic Anhydride

Acetophenone

Trichloroacetic acid

Benzaldehyde

Dichlorvos

2-Butoxyethyl acetate

Acetylsalicylic acid

2-Phenoxycotine

(a)

Tert-Butyl Hydroperoxide

Ethyl chloroacete

Tetramethy

2-(2-Butoxyethoxy)ethanol

5-Amincloicimide

Ethyl acetoacetate

Acetaminophen

Glycerol triacetate

p-Benzoquinone

Acrolein (Acryladehyde)

$$
\begin{gathered}
\text { Caffeine } \\
\text { Ethanol }
\end{gathered}
$$

Acetonitrile

Busulfan

Intracellular

Headspace

Plastic bound

Tetracycline hydrochloride

Acrylamide
Dimethylformamide
Ethylene glycol

Citric acid

Methenamine

Protein bound

$-2.68$

Unbound in medium

Ammonium Chloride
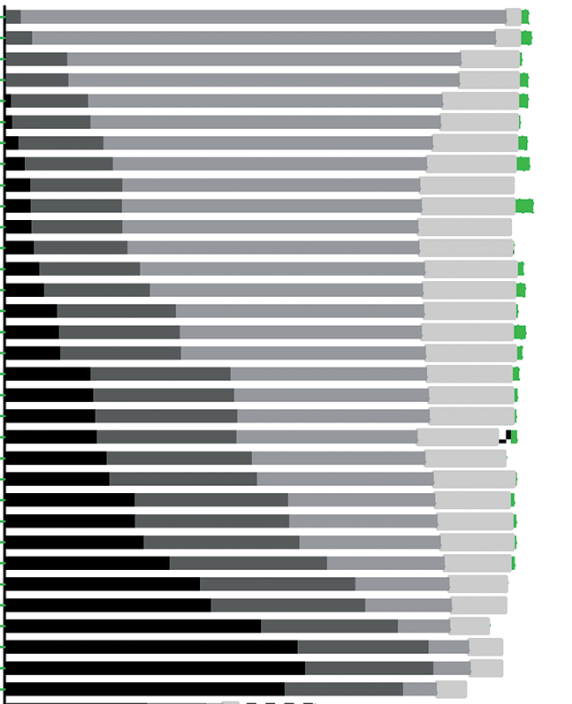

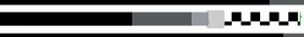
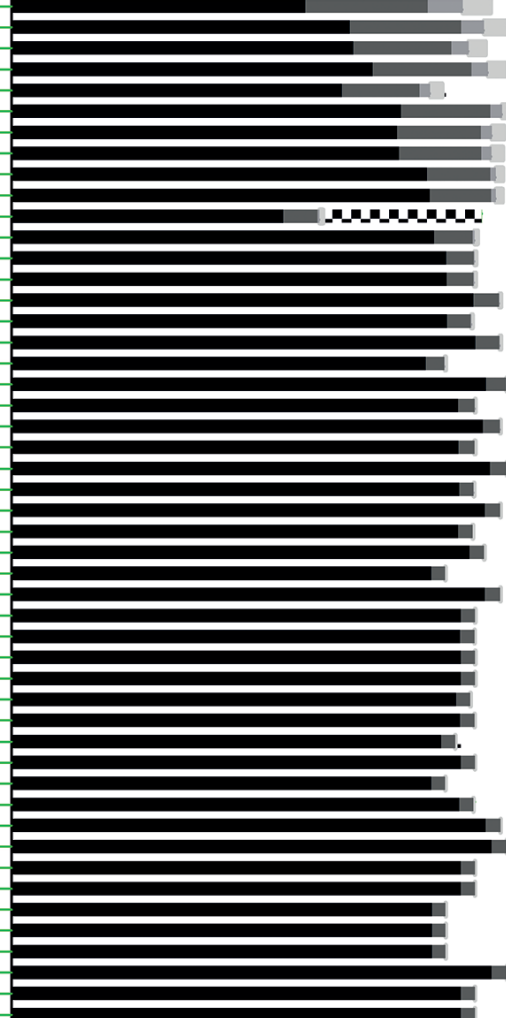

$$
0
$$

50

$\%$ Amount Chemical relative to Nominal Amount

Fig. 3: Calculated percentage of partitioning of the 83 chemicals after 48 hours, relative to the nominal concentration

Figure adapted from Proença et al. (2017); logK $\mathrm{K}_{\text {ow }}$, logarithm of octanol/water partition coefficient 
Tab. 3: Percentage of degraded chemical and parameters describing degradation: air and water degradation rate $\left(\mathrm{s}^{-1}\right)$ and amount of chemical available for degradation (i.e., unbound chemical in medium and evaporated chemical) at 48 hours The green color coding shows a gradient from lower values with light color to higher values with a darker color.

\begin{tabular}{|c|c|c|c|c|}
\hline & $\%$ Deg & $\begin{array}{l}\text { Air } \\
\text { degradation }\left(\mathbf{s}^{-1}\right)\end{array}$ & $\begin{array}{l}\text { Water } \\
\text { degradation }\left(\mathbf{s}^{-1}\right)\end{array}$ & $\begin{array}{l}\% \text { Unbound + \% } \\
\text { evaporated }\end{array}$ \\
\hline Xylene & 38.6 & $1.0 \mathrm{E}-05$ & 5.3E-07 & 44 \\
\hline Ethanol & 14.4 & $2.5 \mathrm{E}-06$ & 9.3E-07 & 83 \\
\hline Glycerol & 14.3 & 1.4E-05 & 9.3E-07 & 83 \\
\hline Citric acid & 14.3 & 5.3E-06 & 9.3E-07 & 83 \\
\hline Ethylene glycol & 14.3 & $5.8 \mathrm{E}-06$ & 9.3E-07 & 83 \\
\hline 2-(2-Butoxyethoxy)ethanol & 14.3 & $5.6 \mathrm{E}-05$ & 9.3E-07 & 83 \\
\hline 2-Butoxyethyl acetate & 14.3 & 1.6E-05 & 9.3E-07 & 82 \\
\hline Diethyl phthalate & 14.3 & $2.2 \mathrm{E}-05$ & 9.3E-07 & 66 \\
\hline Acrolein (acrylaldehyde) & 11.4 & $1.5 \mathrm{E}-05$ & 5.3E-07 & 86 \\
\hline Caprylic acid & 9.0 & 6.3E-06 & 9.3E-07 & 55 \\
\hline p-Benzoquinone & 9.0 & $5.9 \mathrm{E}-06$ & 5.3E-07 & 88 \\
\hline Benzaldehyde & 8.8 & 9.7E-06 & 5.3E-07 & 86 \\
\hline Isopropyl alcohol & 8.6 & 3.8E-06 & 5.3E-07 & 89 \\
\hline Tert-butyl hydroperoxide & 8.6 & $2.2 \mathrm{E}-06$ & 5.3E-07 & 88 \\
\hline Ethyl chloroacetate & 8.6 & $9.1 \mathrm{E}-07$ & 5.3E-07 & 88 \\
\hline Dimethylformamide & 8.5 & 1.3E-05 & 5.3E-07 & 89 \\
\hline Ammonium chloride & 8.5 & $1.9 \mathrm{E}-09$ & 5.3E-07 & 89 \\
\hline Ethyl acetoacetate & 8.5 & $1.5 \mathrm{E}-06$ & 5.3E-07 & 89 \\
\hline Acrylamide & 8.5 & $9.6 \mathrm{E}-06$ & 5.3E-07 & 89 \\
\hline Acetaminophen & 8.5 & 1.3E-05 & 5.3E-07 & 89 \\
\hline 5-Aminosalicylic acid & 8.5 & 1.6E-05 & 5.3E-07 & 89 \\
\hline Glycerol triacetate & 8.5 & $6.4 \mathrm{E}-06$ & 5.3E-07 & 89 \\
\hline Urea & 8.5 & $1.5 \mathrm{E}-06$ & 5.3E-07 & 89 \\
\hline Caffeine & 8.5 & $1.5 \mathrm{E}-05$ & 5.3E-07 & 89 \\
\hline Acetonitrile & 8.5 & 1.3E-07 & 5.3E-07 & 89 \\
\hline 2-Phenoxyethanol & 8.5 & $2.4 \mathrm{E}-05$ & 5.3E-07 & 88 \\
\hline Acetylsalicylic acid & 8.5 & $9.8 \mathrm{E}-07$ & 5.3E-07 & 88 \\
\hline Acetophenone & 8.3 & 2.1E-06 & 5.3E-07 & 86 \\
\hline Phthalic anhydride & 8.2 & $5.6 \mathrm{E}-07$ & 5.3E-07 & 86 \\
\hline Triethylene glycol dimethacrylate & 8.0 & 6.7E-05 & 5.3E-07 & 83 \\
\hline Benzene & 7.2 & $9.2 \mathrm{E}-07$ & 2.1E-07 & 85 \\
\hline Tetramethylthiuram monosulphide & 6.5 & $1.0 \mathrm{E}-04$ & 2.1E-07 & 90 \\
\hline Valproic acid & 6.3 & 6.1E-06 & 5.3E-07 & 68 \\
\hline Propylparaben & 5.1 & 1.1E-05 & 5.3E-07 & 58 \\
\hline Diallyl phthalate & 4.2 & $5.9 \mathrm{E}-05$ & 5.3E-07 & 51 \\
\hline Busulfan & 3.5 & $3.5 \mathrm{E}-06$ & 2.1E-07 & 93 \\
\hline Cycloheximide & 3.5 & 4.9E-05 & $2.1 \mathrm{E}-07$ & 93 \\
\hline Chloral hydrate & 3.5 & $1.4 \mathrm{E}-06$ & 2.1E-07 & 93 \\
\hline Nicotine & 3.5 & $6.8 \mathrm{E}-05$ & 2.1E-07 & 93 \\
\hline Dichlorvos & 3.4 & 7.1E-06 & 2.1E-07 & 91 \\
\hline
\end{tabular}




\begin{tabular}{|c|c|c|c|c|}
\hline & $\%$ Deg & $\begin{array}{l}\text { Air } \\
\text { degradation }\left(\mathbf{s}^{-1}\right)\end{array}$ & $\begin{array}{l}\text { Water } \\
\text { degradation }\left(\mathbf{s}^{-1}\right)\end{array}$ & $\begin{array}{l}\% \text { Unbound + } \\
\% \text { evaporated }\end{array}$ \\
\hline Trichloroacetic acid & 3.4 & $3.9 \mathrm{E}-07$ & 2.1E-07 & 91 \\
\hline 1-Naphthylamine & 3.0 & $1.5 \mathrm{E}-04$ & 2.1E-07 & 83 \\
\hline 2-Chloro-4-nitroaniline & 3.0 & 2.9E-06 & 2.1E-07 & 82 \\
\hline 2,6-Diethylaniline & 2.8 & $1.2 \mathrm{E}-04$ & 2.1E-07 & 76 \\
\hline Carbamazepine & 2.7 & 2.4E-04 & 2.1E-07 & 76 \\
\hline 2,4-Dichlorophenoxyacetic acid & 2.4 & 5.0E-06 & 2.1E-07 & 71 \\
\hline Methenamine & 2.2 & $3.8 \mathrm{E}-04$ & $1.3 \mathrm{E}-07$ & 95 \\
\hline Tetracycline hydrochloride & 2.2 & $1.5 \mathrm{E}-04$ & 1.3E-07 & 95 \\
\hline Chloramphenicol & 2.2 & 2.3E-05 & 1.3E-07 & 94 \\
\hline Colchicine & 2.2 & 7.0E-04 & 1.3E-07 & 94 \\
\hline Diazepam & 2.0 & 7.4E-06 & 2.1E-07 & 67 \\
\hline Ethoxyquin & 1.8 & $1.9 \mathrm{E}-04$ & 2.1E-07 & 58 \\
\hline Warfarin & 1.8 & $1.4 \mathrm{E}-04$ & 2.1E-07 & 59 \\
\hline $\mathrm{N}$-isopropyl-N'-phenyl-p-phenylenediamine & 1.1 & $1.6 \mathrm{E}-04$ & 2.1E-07 & 41 \\
\hline Benzyl benzoate & 0.9 & $5.2 \mathrm{E}-06$ & 5.3E-07 & 20 \\
\hline Triphenyltin hydroxide & 0.7 & 4.5E-06 & 2.1E-07 & 39 \\
\hline Disopyramide & 0.4 & 9.4E-05 & $4.5 \mathrm{E}-08$ & 77 \\
\hline Dibutyl phthalate & 0.3 & 7.0E-06 & 9.3E-07 & 5 \\
\hline Thioridazine hydrochloride & -0.2 & $1.9 \mathrm{E}-04$ & $1.3 \mathrm{E}-07$ & 5 \\
\hline 1,2,3,4-Tetrachlorobenzene & -0.5 & $6.2 \mathrm{E}-08$ & 1.3E-07 & 6 \\
\hline Parathion & -0.6 & $6.9 \mathrm{E}-05$ & 2.1E-07 & 26 \\
\hline 17a-Ethynyloestradiol & -0.7 & 9.4E-05 & 1.3E-07 & 33 \\
\hline Endosulfan & -1.0 & $6.8 \mathrm{E}-06$ & 4.5E-08 & 26 \\
\hline Rifampicin & -1.0 & $6.6 \mathrm{E}-04$ & $4.5 \mathrm{E}-08$ & 21 \\
\hline Lindane & -1.0 & $1.1 \mathrm{E}-07$ & $4.5 \mathrm{E}-08$ & 28 \\
\hline Methadone hydrochloride & -1.0 & $2.9 \mathrm{E}-05$ & 1.3E-07 & 18 \\
\hline 1,2,4-Trichlorobenzene & -1.2 & 4.1E-07 & 1.3E-07 & 21 \\
\hline 4'-Tert-butyl-2'6'-dimethyl-3'5'-dinitroacetophenone & -1.3 & $1.2 \mathrm{E}-06$ & 1.3E-07 & 18 \\
\hline Chlorpromazine hydrochloride & -1.4 & 1.3E-04 & 1.3E-07 & 10 \\
\hline Amitriptyline hydrochloride & -1.6 & $1.2 \mathrm{E}-03$ & 2.1E-07 & 17 \\
\hline Pentachlorophenol & -1.8 & 4.1E-07 & 4.5E-08 & 1 \\
\hline Benz(a)anthracene & -2.0 & $3.8 \mathrm{E}-05$ & 1.3E-07 & 0 \\
\hline Haloperidol & -2.1 & 8.7E-05 & $4.5 \mathrm{E}-08$ & 11 \\
\hline Chloroquine bis(phosphate) & -2.4 & $6.4 \mathrm{E}-05$ & 4.5E-08 & 7 \\
\hline Phenanthrene & -2.8 & $9.8 \mathrm{E}-06$ & 1.3E-07 & 8 \\
\hline D-Amphetamine sulphate & -2.9 & 4.3E-05 & 2.1E-07 & 11 \\
\hline Pyrene & -3.2 & 3.8E-05 & 1.3E-07 & 3 \\
\hline Pentachlorobenzene & -3.3 & 4.3E-08 & $4.5 \mathrm{E}-08$ & 1 \\
\hline Fenpropathrin & -3.3 & $1.3 \mathrm{E}-05$ & $1.3 \mathrm{E}-07$ & 0 \\
\hline Dimethyldioctadecylammonium chloride & -3.4 & 5.2E-05 & $2.1 \mathrm{E}-07$ & 0 \\
\hline Ochratoxin A & -3.7 & $1.9 \mathrm{E}-05$ & 2.1E-07 & 4 \\
\hline Hexachlorophene & -4.0 & $1.6 \mathrm{E}-06$ & $4.5 \mathrm{E}-08$ & 0 \\
\hline Maprotiline & -4.4 & 7.1E-05 & 2.1E-07 & 5 \\
\hline
\end{tabular}




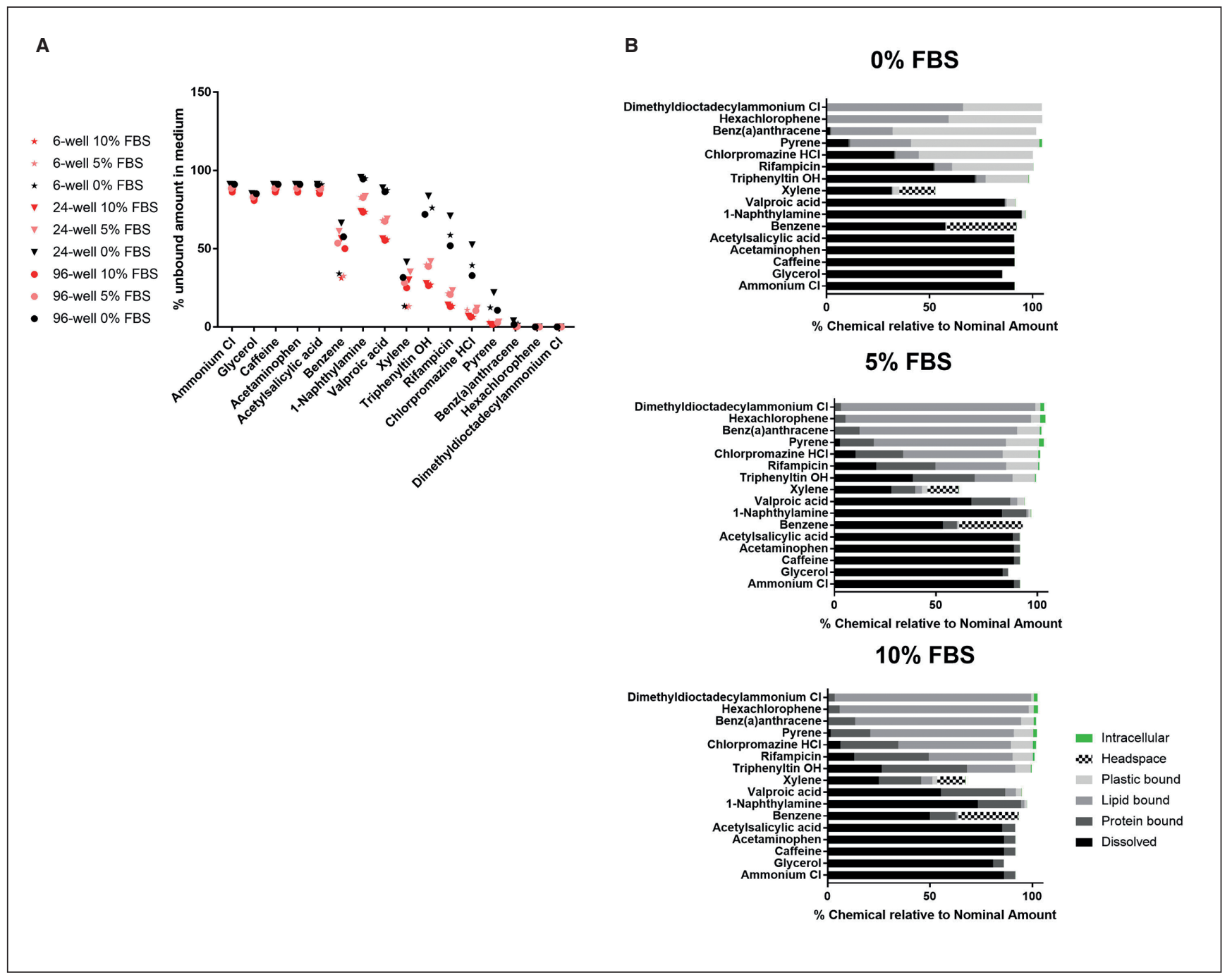

Fig. 4: Percentages of the final partitioned amounts (after 48 hours) relative to the nominal amount (amount indicated in the supplementary file ${ }^{9}$ ) for different experimental set-ups

A) Final unbound amount in medium for different experimental set-ups. B) Percentage of amounts partitioned into the components of the in vitro assay for a 96 -well plate experiment with 0,5 , and $10 \%$ FBS. FBS, fetal bovine serum

including the two chemicals with significant evaporation (benzene and xylene). By using the previously optimized NEC and $\mathrm{Kr}$ values, the compounds' fates were simulated for experiments in 96,24 , and 6-well plates with 0,5 , and $10 \%$ serum.

Xylene had the highest percentage of degradation (Fig. 4B) for all in vitro set-ups. However, a higher $\%$ of serum does reduce degradation by decreasing the amount of free chemical in medium or in headspace. Figure $4 \mathrm{~A}$ also shows the impact of the different percentages of serum supplementation and the microplate configuration on the final unbound amount of chemical in medium relative to the nominal amount. As expected, less serum is related to a higher unbound amount of chemical. However, for highly lipophilic compounds $\left(\log \mathrm{K}_{\mathrm{ow}} \geq 5.76\right)$, there is virtually no unbound fraction in the medium, even with $0 \%$ serum, mainly due to plastic and lipid binding. It is noteworthy that lipids present in the $0 \%$ serum condition are derived from dead cells, as the
VCBA simulates that the lipid content of dead cells is released into the medium. It is evident for the same chemicals that the 6 -well plate, followed by the 24 -well plate, is the plate configuration with the highest unbound chemical concentration, possibly due to higher plastic binding found for the 96-well plate (results not shown).

Figure $4 \mathrm{~B}$ shows a lower percentage of chemical within the cells for the $0 \%$ FBS condition than for $5 \%$ and $10 \%$. Because this percentage reflects the amount in all cells, this means more chemical is being taken up by the cells, inducing toxicity, and thus decreasing the number of cells. In fact, the concentration of chemical in the few live cells remaining in the $0 \% \mathrm{FBS}$ condition is higher.

Although the VCBA simulates a very low percentage of unbound chemical for highly lipophilic chemicals, lipophilicity also determines uptake and bioaccumulation. Therefore, high- 
A

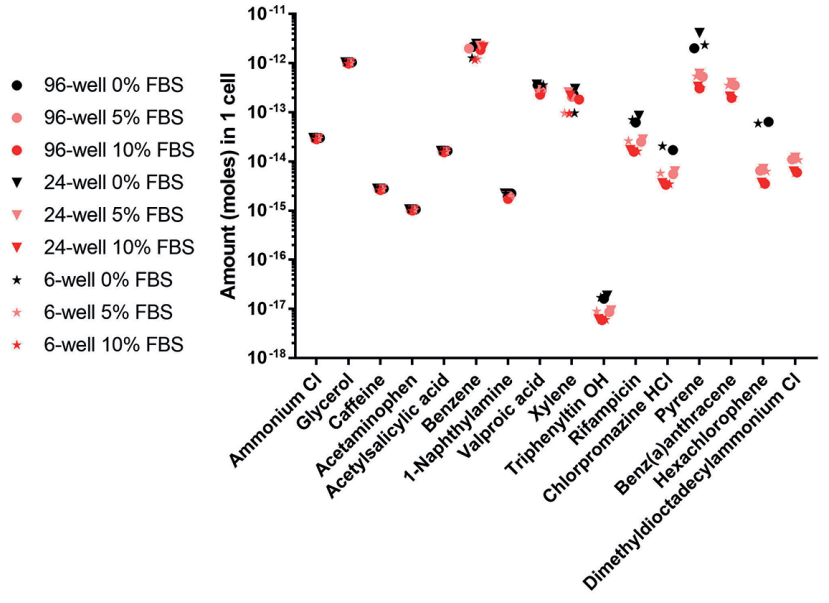

B

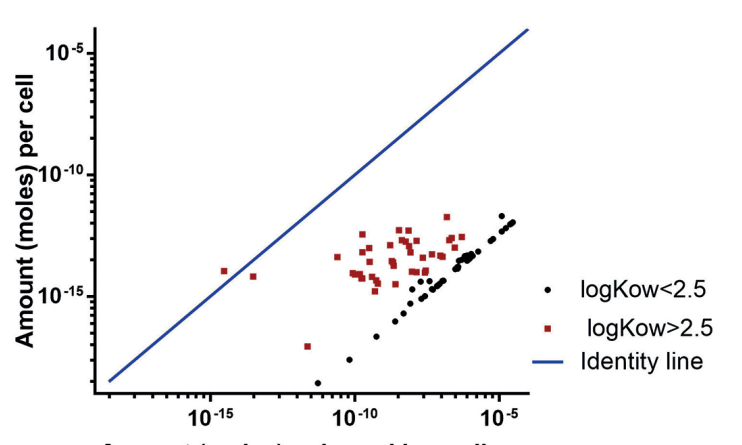

Amount (moles) unbound in medium
logKow $<2.5$ Identity line

Fig. 5: Amounts of intracellular chemicals (moles) per cell in different experimental set-ups

A) Amount of intracellular chemicals for several experimental set-ups. B) Percentage of chemicals per cell vs unbound in medium (for 96-well geometry, 5\% FBS). FBS, foetal bovine serum; log $\mathrm{K}_{\mathrm{ow}}$, the logarithm of octanol/water partition coefficient

er cell permeability compensates to some extent for the lack of bioavailable chemical, as observed in Figure 5A. In fact, by dividing the chemicals into those with $\log \mathrm{K}_{\mathrm{ow}}<2.5$ (hydrophilic) and those with higher values (lipophilic), a different relation of intracellular to unbound amount becomes apparent (Fig. 5B). Chemicals with $\log \mathrm{K}_{\mathrm{ow}}<2.5$ show a linear correlation, while chemicals with $\log \mathrm{K}_{\mathrm{ow}}>2.5$ have more scattered intracellular amounts of chemical. Still, for the same unbound amount, lipophilic chemicals $\left(\log \mathrm{K}_{\mathrm{ow}}>2.5\right)$ show a higher intracellular amount than less lipophilic chemicals.

The more lipophilic the chemical, the more the intracellular amount of chemical per cell varies between experimental set-ups; decreasing with higher serum concentrations but with little difference between the different well geometries. For a few of the most lipophilic chemicals, the intracellular concentration increased such that $0 \%$ FBS was enough to kill all the cells (with NEC and $\mathrm{Kr}$ previously optimized). Evaporation also seems to play a role for intracellular concentration, as both benzene and xylene show the lowest intracellular amounts in the 6-well plate configuration.

\section{Discussion}

VCBA simulations for 83 chemicals were optimized against experimental concentration-response curves. While the VCBA was able to fit the experimental data approximately for most of these chemicals, resulting in small errors, the fit was poor for some chemicals. This was due to their experimental concentration-response curves deviating from the classical form (an inverted logistic sigmoidal curve). Accordingly, when choosing the chemical set, five chemicals were excluded for having concentration-response curves that were considered inadequate (1,1,1-trichloroethane HLC $=1740,1$,2-dichlorobenzene HLC $=$ 195, hexachlorobenzene HLC $=131$, tris(nonylphenyl)phosphite $\mathrm{HLC}=66.2$, 2-ethylhexyl acrylate HLC $=43.8$ ). It is noteworthy that these chemicals all have very high HLC values, suggesting that the difficulty in obtaining a classical concentration-response relationship may be related to the degree of evaporation.

This optimization step is needed for the inclusion of toxicity parameters in a cell growth model that allows the comparison of in vitro toxicity experiments with different assay durations and can give insight into how viability changes in a repeated exposure assay (Paini et al., 2017b).

The VCBA is a flexible model that is capable of adjusting to the variety of experimental set-ups used and facilitates data integration and interpretation. The impact of several biokinetic processes on the chemical concentrations at the end of a 48-hour assay was studied here. The model predictions are a direct result of the model equations for the three main partition constants for lipid, protein, and plastic binding, which are the following:

Plastic partition constant: Kp $=10^{(0.97 * \operatorname{logKow}-6.94)}$

Protein partition constant: $\mathrm{Ks}<-10^{\text {(vals-1.178) }}$

$$
\text { vals }=\left\{\begin{array}{c}
-1.31, \text { if } \log \text { Kow }<1.09 \\
0.57 \times \operatorname{logKow}+0.69, \text { if } 1.09 \leq \operatorname{logKow} \leq 4.6 \\
\operatorname{logKow}-1.3, \text { if } \operatorname{logKow}>4.6
\end{array}\right.
$$

Lipid partition constant: $\mathrm{K} 1<-10^{(1.25 * \operatorname{logKow}-3.70)}$

The binding processes to plastic, protein and lipid will indirectly compete by removing dissolved unbound chemical from the medium. $\log \mathrm{K}_{\mathrm{ow}}$ is a common descriptor of unspecific binding in chemical-biological systems (Caron and Ermondi, 2008) and is 
therefore frequently used in QSARs, including those used in the VCBA. The greater contribution of $\log \mathrm{K}_{\mathrm{ow}}$ to lipid binding than to plastic binding will always dictate a higher binding constant to lipids. Similarly, for proteins, the relationship between $\log \mathrm{K}_{\mathrm{ow}}$ and protein binding depends on the $\log \mathrm{K}_{\mathrm{ow}}$ value. The binding constant for protein is always higher than for plastic and lipids up to a $\log \mathrm{K}_{\mathrm{ow}}$ value of about 6 . For very lipophilic compounds, the binding constants for lipids and proteins are similar. The total binding to each element depends on this binding constant but also on the concentration of proteins and lipids in the medium and on the plastic surface area.

It is noteworthy that although the lipids in medium with $0 \%$ serum should be one eighth of the lipids in 5\% serum after 48 hours, they still have a high binding capacity, as observed in Figure 4. However, two considerations indicate that the $0 \%$ serum plot is most likely far from reality. Firstly, at $0 \%$ serum, most cell lines halt growth and thus the fraction of lipids in the medium would be expected to be even smaller. Secondly, saturation is not included in the simulation. Saturation is not a straightforward phenomenon for lipids, especially because the interaction of lipids with chemicals occurs in the form of aggregates rather than individually (Balaz, 2009). Modelling saturation could furthermore increase the differences among the different percentages of serum supplementation. Although the extent of lipid binding should alert to careful consideration of the chemical's kinetics, high lipid binding may also indicate a mode of toxicity (Armitage et al., 2014) based on narcosis, which can also occur via external cell effects, without complete cell uptake.

While partitioning to plastic does seem (experimentally) to change with nominal concentration (Kramer, 2010), saturation of this process is very likely and was not modelled. Indeed, Wilmes et al. (2013) showed evidence of plastic binding saturation for cyclosporin A. Likewise, protein and lipid binding saturation was also not modelled, and therefore these VCBA estimations are representative of the maximum concentration which will partition to non-aqueous phases. To include saturation for these phases, additional experimental measurements would have to be performed, such as determination of the maximum number of binding sites on serum protein, or the maximum concentration of chemical that can be bound to plastic (Kramer, 2010).

Although the absence of serum leads to a higher unbound chemical concentration in medium, evaporation consequently increases for xylene and benzene in all simulated in vitro set-ups. This is in line with Kramer et al. (2012), who experimentally verified that serum retained phenanthrene in solution. In the same article, a possible deficiency of the model in capturing evaporation was reported, since it uses the HLC obtained/predicted for $20-25^{\circ} \mathrm{C}$ as a proxy of evaporation, while experiments are often run at higher temperatures such as $37^{\circ} \mathrm{C}$ (Kramer et al., 2012). Furthermore, the HLC is dependent on chemical solubility and vapor pressure increases with temperature. It was reported that the HLC increased by about $50 \%$ for chlorobenzene, chlorobiphenyls, and polycyclic aromatic hydrocarbons (Ten Hulscher et al., 1992) when the temperature was increased from 20 to $30^{\circ} \mathrm{C}$.

Evaporation of phenantrene and 1,2,4-trichlorobenzene has been experimentally verified (Kramer et al., 2012), while our model points to only $0.03 \%$ and $2.74 \%$ of the respective chemi- cal in the headspace (at 5\% serum). Several reports (ISO, 2006; OECD, 2000) have indicated that chemicals with $1 \mathrm{~Pa} \times \mathrm{m}^{3} / \mathrm{mol}$ are likely to evaporate, while chemicals with $100 \mathrm{~Pa} \times \mathrm{m}^{3} / \mathrm{mol}$ (which would include 1,2,4-trichlorobenzene) are considered highly volatile. Therefore, we expected higher percentages in the headspace for 1,2,3,4-tetrachlorobenzene, pentachlorobenzene, diethyl phthalate, p-benzoquinone, endosulfan, phenanthrene, ethyl chloroacetate, acetonitrile, benzaldehyde, tetramethylthiuram monosulphide, tert-butyl hydroperoxide, benz(a)anthracene, pyrene, and acetophenone, while, in fact, modelling predicted that less than $0.8 \%$ of any of these chemicals would evaporate.

Furthermore, since evaporation is linked to degradation, the concentrations of volatile chemicals can drop even further during the 48-hour incubation. High evaporation and degradation was found for xylene and benzene in the 6-well plate owing to its higher ratio of headspace to medium volume. For non-volatile chemicals, the 24-well plate seems to retain the highest concentration of unbound chemical in the medium as there is less plastic binding (clearer in $0 \%$ serum conditions), which is related to a relatively lower ratio of plastic surface exposed to medium volume. When choosing the conditions to be simulated, care was taken to maintain the proportions across the experimental set-ups, but differences were still found among the microplate geometries. Hence, when comparing experimental conditions that do not maintain proportions, even greater differences would be expected between the different microplates.

In the current version of the VCBA, cell uptake of chemicals is based entirely on passive diffusion; active transport is not considered. This uptake rate is based on the specific cell surface and the permeability equation suggested by Yazdanian et al. (1998):

Log permeability $=-1.1711+0.98 \log \mathrm{K}_{\mathrm{ow}}-0.0011 \mathrm{MW}$

This equation considers the molecular size and the lipophilicity $\left(\log \mathrm{K}_{\mathrm{ow}}\right)$ of the molecule, which constitute two of the five rules of Lipinski (Lipinski et al., 1997), as essential parameters. The contribution of $\log \mathrm{K}_{\mathrm{ow}}$ to the uptake will compensate, to some extent, the lower concentration of unbound chemical in the medium. Other chemical characteristics, such as the van der Waals surface area, also influence cell uptake. However, calculating these requires powerful computational methods and therefore, for the sake of a higher throughput model, they were not considered here (Yazdanian et al., 1998). As no distinction was made between neutral and charged chemicals, the uptake of charged compounds at $\mathrm{pH} 7.4$ will be overpredicted.

The global applicability of the VCBA, which allows any chemical to be simulated as long as the physicochemical characteristics are known, is based on several assumptions that we briefly highlight here. Firstly, the QSARs used in the VCBA to predict partition coefficients for lipids, serum, and plastic were based mostly on $\log \mathrm{K}_{\mathrm{ow}}$. Other physicochemical properties that are important for fate, such as charge and whether the chemical is an H-donor/H-acceptor, were not included (Goss and Schwarzenbach, 2001). Besides, as described below, these QSARs were derived from specific sets of chemicals.

For plastic, Kramer (2010) analyzed seven polycyclic aromatic hydrocarbons (PAHs) with $\log \mathrm{K}_{\mathrm{ow}}$ values ranging from 3.33 
to 6.13 (and HLC from 0.034 to $45 \mathrm{~Pa} \times \mathrm{m}^{3} / \mathrm{mol}$ ), measuring the binding constants at $1 \%$ maximum water solubility, while for lipids, Jonker and van der Heijden (2007) analyzed 13 PAHs with $\log \mathrm{K}_{\mathrm{ow}}$ values ranging approximately from 4.5 to 7 . To develop the protein partitioning QSAR, chemicals other than PAHs were also considered, as the study was based on six independent studies including 36 chemicals with $\log \mathrm{K}_{\mathrm{ow}}$ ranging from -1.3 to 5.1. PAHs are a family of neutral, non-polar chemicals; hence it is not clear to what extent VCBA outputs for chemicals with different characteristics are reliable. As an example, we considered protein binding as a non-specific interaction, which is not necessarily true for polar, charged, and more lipophobic chemicals (Gülden and Seibert, 2005). For metallo-organic and inorganic chemicals, this uncertainty increases further.

Similar to the QSARs included in the VCBA, some predictive tools and methods for the physicochemical input parameters, such as the ones in EPIsuite and Fuller's method for calculation of SVcomp, are based on organic chemicals. Fuller's method is less precise for inorganic compounds than for organics (error $<10 \%$ ) (Tang et al., 2014).

Despite the assumptions of the VCBA, its simulations show to what extent the unbound concentration can deviate from the nominal concentration as a result of partitioning, evaporation or degradation. This emphasizes the importance of using in vitro fate data in the interpretation of in vitro studies and for in vitro to in vivo extrapolations. As in Gülden and Seibert (2003), the model can be used to separate chemicals into classes to distinguish compounds that are more prone to binding and that, therefore, have bioavailable concentrations that are different from the nominal concentrations. In addition, it can indicate how comparable in vitro toxicity experiments are for a given chemical. In this work, unlike in Gülden and Seibert (2003), a separation of chemicals of low and high in vitro potency is not made, but on the other hand, plastic binding, evaporation, degradation, and cell dilution are included.

Although not shown here, it is noteworthy that using the VCBA final unbound concentrations did not improve, in general, the prediction of in vivo acute oral toxicity (Proença et al., 2017). It is unclear whether this is due to the uncertainties of the VCBA and/ or to the lack of in vitro to in vivo extrapolation (e.g., by PBK modelling). The in vivo dose used here is the nominal oral dose, but a chemical's in vivo kinetics comprise additional processes such as metabolism and absorption through the gastrointestinal tract, which are not accounted for in these comparisons. The cell line used in these assays has no metabolic competence; hence it will not correctly predict compounds that are bio-activated or that are more easily cleared or excreted when metabolized. It is noteworthy that the higher protein-binding ability of lipophilic compounds also includes a higher affinity to enzymes involved in xenobiotic metabolism. Thus, these chemicals tend to be metabolized more commonly than polar compounds (Pirovano et al., 2012), which further explains a lack of a trend between false predictions and high $\log \mathrm{K}_{\mathrm{ow}}$ values. However, a more accurate comparison of in vivo unbound blood plasma concentrations and in vitro unbound medium concentrations would require PBK modelling for all 83 compounds, a task which extends beyond the scope of this specific work.
The best way to integrate the predicted concentrations as a point of departure for extrapolation in risk assessment is still being studied. Can we assume that the unbound concentration reflects the bioavailable concentration, and can this be used as a point of departure for QIVIVE? In this work, the unbound concentration in the medium after 24-48 hours is assumed to be the "toxic dose", while some chemicals cause their toxic effect by being bound to lipids (narcosis) or proteins. Moreover, other dose metrics such as $\mathrm{C}_{\max }$ (maximum concentration) and the area under the concentration-time curve (AUC) are used in concentration-response studies (Groothuis et al., 2013), especially for repeated long-term exposures, which can be modelled by VCBA. The most appropriate dose metric for comparison with in vivo toxicity is an issue that should be further evaluated in the future.

To increase confidence in VCBA simulations, an initial step should be to check some of the simulations experimentally. It would be especially insightful to test compounds representing a wide range of physicochemical properties (e.g., $\log \mathrm{K}_{\mathrm{ow}}$ and HLC). For HLC, the use of a correction factor such as van't Hoff may help to avoid under-prediction of evaporation (Armitage et al., 2014). Besides, the high uncertainty derived from modelling compounds outside the applicability domain of the QSARs included in the VCBA is an issue that needs to be addressed and, ideally, the applicability domains should be widened. Additionally, running local or global sensitivity analysis and uncertainty analysis (UASA) will increase model credibility.

The most direct use of the VCBA, even with all of its uncertainties, is to compare the results of in vitro toxicity assays. This can indicate whether partitioning or biokinetic processes explain differences between toxicity assays, and also whether assays of different durations actually produce the same results once the NEC and $\mathrm{Kr}$ are optimized. Moreover, the VCBA can be run without toxicity data when designing experiments: It can indicate whether a chemical is likely to evaporate, especially considering experiments with higher serum supplementation. Moreover, it gives indications whether a $100 \%$ mass balance can be expected after a chosen assay duration, and in case a specific range of concentrations is to be tested, what nominal concentrations in a specific medium correspond to respective unbound, bioavailable, or intracellular concentrations.

In this work, the VCBA is used to model a fibroblast cell line, where little metabolism and active transport will occur, mitigating the in silico model limitations. When simulating metabolically competent cell lines, such as HepaRG, it should be assessed whether the test chemical is metabolized or whether it is a substrate of specific transporters present in the cell line (Clerbaux et al., 2019). Furthermore, being a dynamic model capable of predicting different dose metrics (final concentration, $\mathrm{C}_{\max }$, etc.) in an in vitro assay, the VCBA can be used to integrate toxicity data obtained by multiple approaches.

In general, the use of the VCBA allows increased confidence in the use of in vitro models for chemical risk assessment.

\section{References}

Andersen, M. E. and Krishnan, K. (1994). Physiologically based pharmacokinetics and cancer risk assessment. Environ Health 
Perspect 102, Suppl 1, 103-108. doi:10.1289/ehp.94102s1103

Armitage, J. M., Wania, F. and Arnot, J. A. (2014). Application of mass balance models and the chemical activity concept to facilitate the use of in vitro toxicity data for risk assessment. Environ Sci Technol 48, 9770-9779. doi:10.1021/es501955g

Balaz, S. (2009). Modeling kinetics of subcellular disposition of hemicals. Chem Rev 109, 1793-1899. doi:10.1021/cr030440j

Bell, S. M., Chang, X., Wambaugh, J. F. et al. (2018). In vitro to in vivo extrapolation for high throughput prioritization and decision making. Toxicol In Vitro 47, 213-227. doi:10.1016/j. tiv.2017.11.016

Caron, G. and Ermondi, G. (2008). Lipophilicity: Chemical nature and biological relevance. In R. Mannhold (ed.), Molecular Drug Properties - Measurement and Prediction (313-329). Weinheim, Germany: Wiley-VCH.

Clerbaux, L. A., Paini, A., Lumen, A. et al. (2019). Membrane transporter data to support kinetically-informed chemical risk assessment using non-animal methods: Scientific and regulatory perspectives. Environ Int 126, 659-671. doi:10.1016/j.envint. 2019.03.003

Coecke, S., Pelkonen, O., Leite, S. B. et al. (2013). Toxicokinetics as a key to the integrated toxicity risk assessment based primarily on non-animal approaches. Toxicol In Vitro 27, 15701577. doi:10.1016/j.tiv.2012.06.012

deBruyn, A. M. H. and Gobas, F. A. (2007). The sorptive capacity of animal protein. Environ Toxicol Chem 26, 1803-1808. doi:10.1897/07-016R.1

Ekwall, B. (1983). Screening of toxic compounds in mammalian cell cultures. Ann N Y Acad Sci 407, 64-77. doi:10.1111/j.1749-6632.1983.tb47814.x

Ferrarini, M., Steimberg, N., Ponzoni, M. et al. (2013). Exvivo dynamic 3-D culture of human tissues in the RCCSTM bioreactor allows the study of multiple myeloma biology and response to therapy. PLoS One 8, e71613. doi:10.1371/journal. pone.0071613

Fuller, E. N., Schetler, P. D. and Giddings, J. C. (1966). A new method for prediction of binary gas - Phase diffusion. Ind Eng Chem 58, 18-27. doi:10.1021/ie50677a007

Fuller, E. N., Ensley, K. and Giddings, J. C. (1969). Diffusion of halogenated hydrocarbons in helium. The effect of structure on collision cross sections. J Phys Chem 73, 3679-3685. doi:10.1021/j100845a020

Gajewska, M., Paini, A., Sala Benito, J. V. et al. (2015). In vitroto-in vivo correlation of the skin penetration, liver clearance and hepatotoxicity of caffeine. Food Chem Toxicol 75, 39-49. doi:10.1016/j.fct.2014.10.017

Goss, K. and Schwarzenbach, Ä. P. (2001). Linear free energy relationships used to evaluate equilibrium partitioning of organic compounds. Environ Sci Technol 35, 1-9. doi:10.1021/ es000996d

Graepel, R., Lamon, L., Asturiol, D. et al. (2017). The virtual cell based assay: Current status and future perspectives. Toxicol In Vitro 45, 258-267. doi:10.1016/j.tiv.2017.01.009

Groothuis, F. A., Heringa, M. B., Nicol, B. et al. (2013). Dose metric considerations in in vitro assays to improve quantitative in vitro-in vivo dose extrapolations. Toxicology 332, 30-40. doi:10.1016/j.tox.2013.08.012
Gülden, M., Mörchel, S. and Seibert, H. (2001). Factors influencing nominal effective concentrations of chemical compounds in vitro: Cell concentration. Toxicol In Vitro 15, $233-$ 243. doi:10.1016/S0887-2333(02)00014-0

Gülden, M. and Seibert, H. (2003). In vitro-in vivo extrapolation: Estimation of human serum concentrations of chemicals equivalent to cytotoxic concentrations in vitro. Toxicology 189, 211-222. doi:10.1016/S0300-483X(03)00146-X

Gülden, M. and Seibert, H. (2005). Impact of bioavailability on the correlation between in vitro cytotoxic and in vivo acute fish toxic concentrations of chemicals. Aquat Toxicol 72, 327-337. doi:10.1016/j.aquatox.2005.02.002

Heringa, M. B., Schreurs, R. H., Busser, F. et al. (2004). Toward more useful in vitro toxicity data with measured free concentrations. Environ Sci Technol 38, 6263-6270. doi:10. $1021 / \mathrm{es} 049285 \mathrm{w}$

ISO - International Organization for Standardization (2006). ISO 14442 Water quality - Guidelines for algal growth inhibition tests with poorly soluble materials, volatile compounds, metals and waste water. https://www.iso.org/obp/ui/\#iso:std:iso:14442:ed2:v1:en

Jonker, M. T. O. and van der Heijden, S. A. (2007). Bioconcentration factor hydrophobicity cutoff: An artificial phenomenon reconstructed. Environ Sci Technol 41, 7363-7369. doi:10.1021/es0709977

Kramer, N. I. (2010). Measuring, modeling, and increasing the free concentration of test chemicals in cell assays. Utrecht University. https://dspace.library.uu.nl/handle/1874/37545

Kramer, N. I., Krismartina, M., Rico-Rico, A. et al. (2012). Quantifying processes determining the free concentration of phenanthrene in basal cytotoxicity assays. Chem Res Toxicol 25, 436-445. doi:10.1021/tx200479k

Lipinski, C. A., Lombardo, F., Dominy, B. W. and Feeney, P. J. (1997). Experimental and computational approaches to estimate solubility and permeability in drug discovery and develop ment settings. Adv Drug Deliv Rev 23, 3-25. doi:10.1016/S0169409X(96)00423-1

Louisse, J., Beekmann, K. and Rietjens, I. M. (2016). Use of physiologically based kinetic modeling-based reverse dosimetry to predict in vivo toxicity from in vitro data. Chem Res Toxicol 30, 114-125. doi:10.1021/acs.chemrestox.6b00302

Lu, J., Goldsmith, M. R., Grulke, C. M. et al. (2016). Developing a physiologically-based pharmacokinetic model knowledgebase in support of provisional model construction. PLoS Comput Biol 12, 1-22. doi:10.1371/journal.pcbi.1004495

Madureira, D. J., Weiss, F. T., Van Midwoud, P. et al. (2014). Systems toxicology approach to understand the kinetics of benzo(a)pyrene uptake, biotransformation, and DNA adduct formation in a liver cell model. Chem Res Toxicol 27, 443-453. doi:10.1021/tx400446q

$\mathrm{NIH}$ - National Institutes of Helath (2006). Background Review Document (BRD): Validation of Neutral Red Uptake Test Methods NIH/In Vitro Cytotoxicity Test Methods for Estimating Acute Systemic Toxicity. National Institutes of Health, Publication No. 07-4518. https://bit.ly/2QKMiB6

OECD (2000). Guidance document on aquatic toxicity testing of difficult substances and mixtures. Series on Testing and 
Assessment $N^{\circ} 23$. OECD Publishing, Paris. https://bit. ly/2HHG5mD

Paini, A., Sala Benito, J. V., Bessems, J. and Worth, A. P. (2017a). From in vitro to in vivo: Integration of the virtual cell based assay with physiologically based kinetic modelling. Toxicol In Vitro 45, 241-248. doi:10.1016/j.tiv.2017.06.015

Paini, A., Mennecozzi, M., Horvat, T. et al. (2017b). Practical use of the virtual cell based assay: Simulation of repeated exposure experiments in liver cell lines. Toxicol In Vitro 45, 233-240. doi:10.1016/j.tiv.2016.10.007

Paini, A., Leonard, J. A., Joossens, E. et al. (2019). Next generation physiologically based kinetic (NG-PBK) models in supportof regulatory decision making. Comput Toxicol 9, 61-72. doi:10.1016/j.comtox.2018.11.002

Pirovano, A., Huijbregts, M. A., Ragas, A. M. and Hendriks, A. J. (2012). Compound lipophilicity as a descriptor to predict binding affinity $\left(1 / \mathrm{K}_{\mathrm{m}}\right)$ in mammals. Environ Sci Technol 46, 5168-5174. doi:10.1021/es204506g

Prieto, P., Kinsner-Ovaskainen, A., Stanzel, S. et al. (2013a). The value of selected in vitro and in silico methods to predict acute oral toxicity in a regulatory context: Results from the European Project ACuteTox. Toxicol In Vitro 27, 1357-1376. doi:10.1016/j.tiv.2012.07.013

Prieto, P., Cole, T., Curren, R. et al. (2013b). Assessment of the predictive capacity of the $3 \mathrm{~T} 3$ neutral red uptake cytotoxicity test method to identify substances not classified for acute oral toxicity (LD50 > $2000 \mathrm{mg} / \mathrm{kg}$ ): Results of an ECVAM validation study. Regul Toxicol Pharmacol 65, 344-365. doi:10.1016/j. yrtph.2012.11.013

Proença, S., Paini, A., Joossens, E. et al. (2017). Application of the Virtual Cell Based Assay for Simulation of in vitro Chemical fate following Acute Exposure. JRC Report EUR 28694 EN. Publications Office of the European Union, Luxembourg. http:// publications.jrc.ec.europa.eu/repository/handle/JRC107407

Sala Benito, J. V., Paini, A., Richarz, A. N. et al. (2017). Automated workflows for modelling chemical fate, kinetics and toxicity. Toxicol In Vitro 45, 249-257. doi:10.1016/j.tiv.2017.03.004

Schirmer, K. (2006). Proposal to improve vertebrate cell cultures to establish them as substitutes for the regulatory testing of chemicals and effluents using fish. Toxicology 224, 163-183. doi:10.1016/j.tox.2006.04.042

Seibert, H., Mörchel, S. and Gülden, M. (2002). Factors influencing nominal effective concentrations of chemical compounds in vitro: Medium protein concentration. Toxicol In Vitro 16, 289297. doi:10.1016/S0887-2333(02)00014-0

Stadnicka-Michalak, J., Tanneberger, K., Schirmer, K. and Ashauer, R. (2014). Measured and modeled toxicokinetics in cultured fish cells and application to in vitro - In vivo toxicity extrapolation. PLoS One 9, e92303. doi:10.1371/journal.pone.0092303

Tang, M. J., Cox, R. A. and Kalberer, M. (2014). Compilation and evaluation of gas phase diffusion coefficients of reactive trace gases in the atmosphere: Volume 1. Inorganic compounds. Atmos Chem Phys 14, 9233-9247. doi:10.5194/acp-14-9233-2014

Ten Hulscher, T. E. M., Van Der Velde, L. E. and Bruggeman, W. A. (1992). Temperature sependence of Henry's law constants for selected chlorobenzenes, polychlorinated biphenyls and polycyclic aromatic hydrocarbons. Environ Toxicol Chem 11, 1595-1603. doi:10.1002/etc.5620111109

Wilmes, A., Limonciel, A., Aschauer, L. et al. (2013). Application of integrated transcriptomic, proteomic and metabolomic profiling for the delineation of mechanisms of drug induced cell stress. $J$ Proteomics 79, 180-194. doi:10.1016/j.jprot.2012.11.022

Worth, A. P., Louisse, J., Macko, P. et al. (2017). Virtual cell based assay simulations of intra-mitochondrial concentrations in hepatocytes and cardiomyocytes. Toxicol In Vitro 45, 222-232. doi:10.1016/j.tiv.2017.09.009

Yazdanian, M., Glynn, S. L., Wright, J. L. and Hawi, A. (1998). Correlating partitioning ad Cacao-2 cell permeability of structurally diverse small molecular weight compounds. Pharm Res 15, 1490-1494. doi:10.1023/A:1011930411574

Zaldívar Comenges, J. M., Mennecozzi, M., Marcelino Rodrigues, R. and Bouhifd, M. (2010). A biology-based dynamic approach for the modelling of toxicity in cell-based assays. Part I: Fate modelling. JRC Report EUR 24374 EN. Publications Office of the European Union, Luxembourg. doi:10.2788/94002

Zaldívar Comenges, J. M., Mennecozzi, M., Macko, P. et al. (2011). A biology-based dynamic approach for the modelling of toxicity in cell assays: Part II: Models for cell population growth and toxicity. JRC Report EUR 24374 EN. Publications Office of the European Union, Luxembourg. doi:10.2788/61603

Zaldívar, J. M. and Baraibar, J. (2011) A biology-based dynamic approach for the reconciliation of acute and chronic toxicity tests: Application to Daphnia magna. Chemosphere 82, 15471555. doi:10.1016/j.chemosphere.2010.11.062

Zaldívar Comenges, J. M., Joossens, E., Benito J. V. S. et al. (2017). Theoretical and mathematical foundation of the virtual cell based assay - A review. Toxicol In Vitro 45, 209-221. doi:10.1016/j.tiv.2016.07.013

\section{Conflict of interest}

The authors declare that they have no conflict of interest to disclose. 